\title{
Radiation exposure triggers the malignancy of non-small cell lung cancer cells through the activation of visfatin/Snail signaling
}

\author{
LIANG XIAO $^{1 *}$, YIWEN MAO $^{2 *}$, ZHUTING TONG $^{1}$, YE ZHAO $^{2}$, HAO HONG $^{1}$ and FAN WANG ${ }^{1}$ \\ ${ }^{1}$ Department of Radiation Oncology, The First Affiliated Hospital of Anhui Medical University; \\ ${ }^{2}$ Teaching and Research Section of Nuclear Medicine, Anhui Medical University, Hefei, Anhui 230022, P.R. China
}

Received April 10, 2020; Accepted December 2, 2020

DOI: $10.3892 /$ or.2021.7929

\begin{abstract}
It is estimated that one-half of patients with non-small cell lung cancer (NSCLC) undergo radiotherapy worldwide. However, the outcome of radiotherapy alone is not always satisfactory. The aim of the present study was to evaluate the effects of radiotherapy on the malignancy of NSCLC cells. It was demonstrated that radiation therapy could increase the migration and invasion of NSCLC cells in vitro. Moreover, the upregulation of visfatin, a 52-kDa adipokine, mediated radiation-induced cell motility. A neutralizing antibody specific for visfatin blocked radiation-induced cell migration. Radiation and visfatin induced the expression of Snail, a key molecule that regulates epithelial to mesenchymal transition in NSCLC cells. Furthermore, visfatin positively regulated the mRNA stability of Snail in NSCLC cells, but had no effect on its protein degradation. This may be explained by visfatin-mediated downregulation of microRNA (miR)-34a, which was shown to bind the 3' untranslated region of Snail mRNA to promote its decay. Collectively, these findings suggested that radiation could induce cell motility in NSCLC cells through visfatin/Snail signaling.
\end{abstract}

\section{Introduction}

As the leading cause of cancer mortality, lung cancer accounts for $18.2 \%$ of total cancer deaths worldwide (1). Furthermore, $\sim 80 \%$ of patients with lung cancer patients have non-small-cell lung cancer (NSCLC). The incidence of NSCLC has increased in women during the last two decades worldwide (2). It has been reported that the 5-year survival rate of NSCLC is $<15 \%$ (3). Surgical resection, conventional chemotherapy

Correspondence to: Professor Fan Wang, Department of Radiation Oncology, The First Affiliated Hospital of Anhui Medical University, 218 Jixi Road, Hefei 230022, P.R. China

E-mail: wangfan@ahmu.edu.cn

*Contributed equally

Key words: radiation, non-small cell lung cancer, Snail, visfatin, microRNA-34a and radiotherapy are widely used for the clinical treatment of patients with NSCLC (4).

During the course of treatment, one-half of all patients with NSCLC patients undergo radiotherapy (5). It has been reported that early-stage patients can benefit from stereotactic body radiation therapy (6). Stereotactic body radiation therapy has been used as a standard care modality in medically inoperable patients with early-stage NSCLC (7). However, previous studies have indicated that the outcome of radiotherapy alone is not always satisfactory (8), which may be due to the development of radiotherapy resistance $(9,10)$. Moreover, laboratory and clinical data indicated that radiotherapy may cause clinical adverse effects for patients with NSCLC. For example, radiotherapy can increase tumor invasion and metastasis by upregulating TGF $\beta$-1 expression (11). Cancer cells treated with radiation acquire mesenchymal-like morphology (12). X-ray irradiation can also increase the invasion of NSCLC cells (13). In addition, radiation can stimulate the malignancy of residual, incompletely treated and viable tumors surrounding the treatment zone $(14,15)$. Thus, understanding the mechanisms involved in radiation-induced malignancy in NSCLC cells is needed in order to improve the therapeutic efficacy of radiotherapy.

Cytokines, such as visfatin, are involved in the progression of NSCLC (16). It has been reported that visfatin mediates doxorubicin (Dox) resistance of human NSCLC cells through Akt-mediated upregulation of ATP-binding cassette subfamily C member 1 (17). Furthermore, visfatin triggers cell motility of NSCLC cells by increasing the expression of matrix metalloproteinases (MMPs) (18). Targeted inhibition of visfatin has been proposed as a potential therapeutic approach for NSCLC treatment (19). Visfatin is a cytokine synthesized and released by adipocytes and inflammatory cells (20). Its expression can also be induced during radiation therapy in cancer tissues $(21,22)$. However, whether visfatin is involved in radiation-induced malignancy of NSCLC remains unknown.

Epithelial-mesenchymal transition (EMT) is the first step of tumor metastasis (23) and is critical to the progression and metastasis of NSCLC (24). During EMT, transcription factors, such as Snail, can bind to the E-box motif of the E-cadherin (E-Cad) gene promoter and inhibit its expression $(25,26)$. In a previous study, high protein expression of Snail is detectable in $21 \%$ of NSCLC samples (27). The levels of Snail are associated with poor prognosis in patients with NSCLC (28). It has been reported that the protein expression 
of Snail is essential for EMT induction in NSCLC cells (29). In the present study, the expression levels of cytokines, such as IL-6, IL-8, IL-10, VEGFA, TGF- $\beta$, TNF- $\alpha$ and visfatin were examined in NSCLC cell lines treated with radiation. Further, the potential roles and mechanisms of visfatin in radiation-induced migration and invasion of NSCLC cells were investigated.

\section{Materials and methods}

Cell culture and radiation treatment. The human NSCLC A549 and H1299 cell lines and human bronchial epithelial cells (HBEpC) were purchased from American Type Culture Collection and maintained in DMEM (Invitrogen; Thermo Fisher Scientific, Inc.) supplemented with 10\% FBS (Gibco; Thermo Fisher Scientific, Inc.), penicillin and streptomycin at $37^{\circ} \mathrm{C}$ in $5 \% \mathrm{CO}_{2}$. Mycoplasma contamination was monitored weekly during experiments. Radiation treatment was conducted according to a previous study (30). Briefly, $5 \times 10^{5}$ cells/well were seeded in a 6 -well plate and were irradiated at room temperature using a $6 \mathrm{MV}$ X-ray linear accelerator (Varian 23Ex; Varian Inc.) at a dose rate of $300 \mathrm{cGy} / \mathrm{min}$ for the time required to apply the dose used in each assay. In order to determine the role of visfatin, anti-visfatin neutralizing antibody $(100 \mathrm{ng} / \mathrm{ml})$ or recombinant-visfatin (rVisfatin;100 ng/ml) were added into culture medium for $24 \mathrm{~h}$ at $37^{\circ} \mathrm{C}$ in $5 \% \mathrm{CO}_{2}$, then irradiated at room temperature.

Reagents. Scramble negative control (NC) microRNA (miR, 5'-UUCUCCGAACGUGUCACGUTT-3'), miR-34a inhibitor (5'-AAGCUCCAUUUCGCAACCUUAC-3'), small interfering RNA (siRNA) NC (si-NC; 5'-GCACAACAAGCCGAAUACA-3') and siRNA targeting Snail (5'-CAUCCGAAGCCACACG CUG-3') were purchased from Sigma-Aldrich; Merck KGaA. The neutralizing antibody specific for visfatin (anti-Visfatin; cat. no. A300-778A) and recombinant visfatin (cat. no. RP-75758) were obtained from Invitrogen; Thermo Fisher Scientific, Inc.

Wound healing and Transwell Matrigel ${ }^{T M}$ assay. Cells $\left(1.5 \times 10^{6}\right.$ cells per well) were plated in 12 -well plates and cultured to $80 \%$ confluence in complete medium. The cell layer was scratched with a $200 \mu$ l pipette tip, washed twice with PBS, then cultured with medium containing $0.5 \%$ FBS, with or without the indicated treatments, as described in Figure legends. The migration distance was recorded in the same visual fields under a phase-contrast microscope. The relative migration rate was calculated according to a previous study (31), using the following formula: [(scratch area at $0 \mathrm{~h}$-scratch area at $48 \mathrm{~h}$ )/scratch area at $0 \mathrm{~h}] \times 100 \%$.

Cell invasion was assessed using a Transwell Matrigel invasion chamber ( $8-\mu \mathrm{m}$ pore filters; Corning, Inc.) according to the manufacturer's instructions. A total of $2 \times 10^{5}$ cells was seeded into the upper chamber of a 24-well chamber with FBS-free medium. The bottom chamber received $0.6 \mathrm{ml}$ complete medium. After the indicated treatment and culture for $24 \mathrm{~h}$, the invading cells were fixed using methanol for $15 \mathrm{~min}$ at room temperature, dried under a laminar flow safety cabinet, stained with $0.5 \%$ crystal violet (Sigma-Aldrich; Merck KGaA) for $2 \mathrm{~h}$ at room temperature, then observed under an inverted optical microscope. The number of invading cells in five randomly selected fields of view was quantified using ImageJ software version 1.47 (National Institutes of Health). The relative invasion rate was calculated by dividing the number of stained cells by the number of stained cells in the control group.

Reverse transcription-quantitative (RT- $q$ ) PCR analysis. Total RNA was isolated using TRIzol ${ }^{\circledR}$ reagent (Invitrogen; Thermo Fisher Scientific, Inc.). cDNA was generated by using the PrimeScript RT reagent kit with gDNA Eraser (Takara Biotechnology Co., Ltd.) for mRNA at $37^{\circ} \mathrm{C}$ for $15 \mathrm{~min}$, or the qScript microRNA cDNA synthesis kit (Quantabio) for miRNA at $37^{\circ} \mathrm{C}$ for $60 \mathrm{~min}$ followed by $5 \mathrm{~min}$ at $70^{\circ} \mathrm{C}$, respectively. For mRNA targets, qPCR was conducted using a SYBR-Green PCR Kit (Qiagen GmbH) on the Step-One Plus Real-Time PCR System (Applied Biosystems, Inc.). The thermocycling conditions consisted of an initial denaturation at $95^{\circ} \mathrm{C}$ for $5 \mathrm{~min}$, followed by 50 cycles at $95^{\circ} \mathrm{C}$ for $15 \mathrm{sec}$ and $60^{\circ} \mathrm{C}$ for $30 \mathrm{sec}$. The primer sequences were as follows: i) IL-6 forward, $5^{\prime}-\mathrm{CCT}$ CCAGAACAGATTTGAGAGTAGT-3' and reverse, 5'-GGG TCAGGGGTGGTTATTGC-3'; ii) IL-8 forward, 5'-GAGAGT GATTGAGAGTGGACCAC-3' and reverse, 5'-CACAACCCT CTGCACCCAGTTT-3'; iii) IL-10 forward, 5'-GTGGCATTC AAGGAGTACCTC-3' and reverse, 5'-TGATGGCCTTCGAT TCTGGATT-3';iv) VEGFA forward,5'-TACCTCCACCATGCC AAGTGGT-3' and reverse, 5'-AGGACGGCTTGAAGATG TAC-3'; v) TGF- $\beta$ forward, 5'-GGCCAGATCCTGTCCAAGC-3' and reverse, 5'-GTGGGTTTCCACCATTAGCAC-3'; vi) TNF- $\alpha$ forward, 5'-CCTCTCTCTAATCAGCCCTCTG-3' and reverse, 5'-GAGGACCTGGGAGTAGATGAG-3'; vii) visfatin forward, 5'-AGGGTTACAAGTTGCTGCCACC-3' and reverse, 5'-CTCCACCAGAACCGAAGGCAAT-3'; viii) Snail forward, 5'-GACCACTATGCCGCGCTCTT-3' and reverse, 5'-TCGCTGTAGTTAGGCTTCCGATT-3'; ix) Slug forward, 5'-AGCAGTTGCACTGTGATGCC-3' and reverse, 5'-ACACAGCAGCCAGATTCCTC-3'; x) Twist forward, 5'-CGG ACAAGCTGAGCAAGATT-3' and reverse, 5'-CCTTCTCT GGAAACAATGAC-3'; xi) Zeb1 forward, 5'-GCACCTGAAGA GGACCAGAG-3' and reverse, 5'-TGCATCTGGTGTTCCAT TTT-3'; xii)GAPDHforward,5'-GTCAACGGATTTGGTCTGT ATT-3' and reverse, 5'-AGTCTTCTGGGTGGCAGTGAT-3'.

For miR targets (miR-137, miR-34a, miR-153 and miR-22), qPCRs were performed using the NCode miRNA qRT-PCR analysis kit (Invitrogen; Thermo Fisher Scientific, Inc.). The thermocycling conditions included an initial denaturation at $95^{\circ} \mathrm{C}$ for $3 \mathrm{~min}$ followed by 40 cycles at $95^{\circ} \mathrm{C}$ for $15 \mathrm{sec}$ and $60^{\circ} \mathrm{C}$ for $30 \mathrm{sec}$. The forward primer is the exact sequence of the mature miRNA. The forward primer for U6 was 5'-TGCGGGTGCTCGCTTCGCAGC-3'. Gene expression levels were calculated using the $2^{-\Delta \Delta C q}$ method (32) and standardized to GAPDH and U6 for mRNA and miR targets, respectively. All RT-qPCR reactions were performed three times.

Western blot analysis. Cells were lysed using RIPA buffer (Beyotime Institute of Biotechnology) and protein extracts were collected. Protein concentration was measured using a BCA Protein Assay Kit (Pierce ${ }^{\mathrm{TM}}$; Thermo Fisher Scientific, Inc.). After denaturation in boiling water for $10 \mathrm{~min}$, proteins (20 $\mu \mathrm{g}$ per lane) were separated by SDS-PAGE on $10 \%$ gels, then transferred to PVDF membranes. The membranes were blocked with 5\% skimmed milk at room temperature for $2 \mathrm{~h}$, 
and then incubated with primary antibodies at $4{ }^{\circ} \mathrm{C}$ for at least $15 \mathrm{~h}$. The primary antibodies used were specific for GAPDH (cat. no. ab9485; Abcam; 1:1,000), E-Cad (cat. no. 14472S; Cell Signaling Technology, Inc.; 1:1,000) and Snail (cat. no. ab82846; Abcam; 1:1,000). Membranes were incubated with HRP-conjugated secondary antibodies (cat. no. ab7090; Abcam; 1:10,000 dilution) for $90 \mathrm{~min}$ at $25^{\circ} \mathrm{C}$. The protein were visualized using RapidStep ${ }^{\mathrm{TM}}$ ECL detection reagent (EMD Millipore) in a GeneGnome XRQ Chemiluminescence Imaging System (Syngene). The gray values were analyzed using the ImageJ software (version 1.46; National Institutes of Health). GAPDH primary antibody was used as a control.

ELISA. The levels of visfatin in culture medium were measured using the Nampt/Visfatin human ELISA kit (cat. no. RAG004R; BioVendor R\&D) according to the manufacturer's instructions. The absorbance was measured at $450 \mathrm{~nm}$ using a microplate reader (BioTek Instruments, Inc.)

Protein and mRNA stability assay. Protein and mRNA stability was evaluated as previously reported $(33,34)$. Briefly, cells were treated with $10 \mu \mathrm{g} / \mathrm{ml}$ cycloheximide (CHX; Sigma-Aldrich; Merck KGaA) or $5 \mu \mathrm{g} / \mathrm{ml}$ actinomycin-D (Act-D; Sigma-Aldrich; Merck KGaA ) for the indicated time periods. mRNA and protein expression levels were measured by RT-qPCR and western blot analysis, respectively.

Dual luciferase reporter assay. Dual luciferase reporter assays were carried out as described previously (35). Briefly, the wild-type (WT) Snail 3'-unstranslated region (3'-UTR) luciferase vector containing the putative binding site for miR-34a was purchased from OriGene Technologies, Inc., then mutated using the QuickChange Mutagenesis kit (Stratagene) to produce the mutant (MUT) Snail 3'-UTR construct. Both WT and mutant Snail 3'-UTR were subcloned into the pmiR-GLO plasmid (Promega Corporation). A549 cells in 96 -well plate $\left(5 \times 10^{3}\right.$ cells/well) were transfected with the pmiR-GLO-WT or pmiR-GLO-Mut, together with scramble control or miR-34a inhibitor for $24 \mathrm{~h}$. The activity was measured immediately at the end of the transfection period. Luciferase activity was analyzed as previously reported (35) using the Dual-Luciferase ${ }^{\circledR}$ Reporter Assay system (Promega Corporation). The Firefly luciferase activity was normalized to Renilla luciferase activity.

Cell transfection. All miRNA mimics, inhibitors, siRNAs and the respective negative control were transfected using Lipofectamine ${ }^{\circledR} 2000$ (Invitrogen; Thermo Fisher scientific, Inc.) according to the manufacturer's protocol at concentration of $10 \mathrm{nmol} / \mathrm{l}$ in transfection medium ( $\alpha$ MEM with $10 \%$ fetal calf serum, both from Thermo Fisher Scientific, Inc.). Briefly, cells were cultured to 50-60\% confluence. The culture medium was then replaced with transfection medium. After incubation with RNA oligonucleotides for $6 \mathrm{~h}$, the transfection medium was replaced with full medium, and the cells were incubated for another 24 or $48 \mathrm{~h}$ before harvest.

Statistical analysis. Data are presented as the mean \pm SD of three independent experiments and analyzed using SPSS 20 (IBM Corp.). Differences between two experimental groups were assessed using unpaired Student's t-test (two-tailed). One-way ANOVA followed by Tukey's post hoc test was used when making pairwise comparisons among $\geq 3$ groups. $\mathrm{P}<0.05$ was considered to indicate a statistically significant difference.

\section{Results}

Radiation increases the motility of NSCLC cells. In order to evaluate the potential effects of radiation on the characteristics of NSCLC cells, A549 and H1299 were treated cells with 5 Gy of radiation according to previous studies (30,36-38). This radiation dose significantly increased the in vitro migration rate of both A549 (Fig. 1A) and H1299 (Fig. 1B) cells. A Transwell invasion assay confirmed that $5 \mathrm{~Gy}$ of radiation could increase the in vitro invasion of both A549 and H1299 cells (Fig. 1C). Moreover, the expression of E-Cad in cells was measured following incubation with 1-10 Gy of radiation. Radiation decreased the mRNA expression levels of E-Cad in both A549 and H1299 cells in a dose-dependent manner (Fig. 1D). Western blot analysis confirmed that radiation reduced E-Cad protein expression in A549 and H1299 cells (Fig. 1E). These findings suggested that radiation increased the motility of NSCLC cells.

Radiation increases the expression of visfatin in NSCLC cells. It has been suggested that cytokine levels are critical for the metastasis of NSCLC cells and might be modulated by radiation (16,39). The expression levels of IL-6, IL-8, IL-10, VEGFA, TGF- $\beta$, TNF- $\alpha$ and visfatin were therefore measured, since these cytokines have been shown to be critical for the motility and metastasis of NSCLC cells $(40,41)$. Radiation significantly increased the expression of visfatin in both A549 (Fig. 2A) and H1299 (Fig. 2B) cells. Radiation-induced expression of visfatin was also confirmed in both cell lines using ELISA (Fig. 2C). Furthermore, RT-qPCR demonstrated that radiation increased mRNA expression of visfatin in A549 cells in a dose-dependent manner (Fig. 2D). RT-qPCR (Fig. 2E) and ELISA (Fig. 2F) also indicated that visfatin expression was significantly increased in A549 and H1299 cells, compared with HBEpCs.

Visfatin is essential for radiation induced cell motility. Previous studies have indicated that visfatin is critical for NSCLC development and malignancy $(18,42)$. Thus, to determine whether visfatin was involved in radiation-regulated cell motility, cells were treated with a visfatin neutralizing antibody. Would healing assays indicated that visfatin blockade inhibited migration in A549 cells, both under control conditions and following irradiation (Fig. 3A). Similarly, a Transwell invasion assay also confirmed that the anti-visfatin antibody inhibited radiation-induced invasion of A549 cells (Fig. 3B). Furthermore, visfatin blockade reversed the radiation-induced downregulation of E-Cad, both in A549 (Fig. 3C) and in H1299 (Fig. 3D) cells.

Snail is involved in radiation-and visfatin-induced cell migration. Since E-Cad was significantly decreased during radiation-induced cell migration, it was hypothesized that EMT-TF such as Snail, Slug, Twist, and Zeb1 might be involved in this process. Radiation significantly increased the mRNA expression 

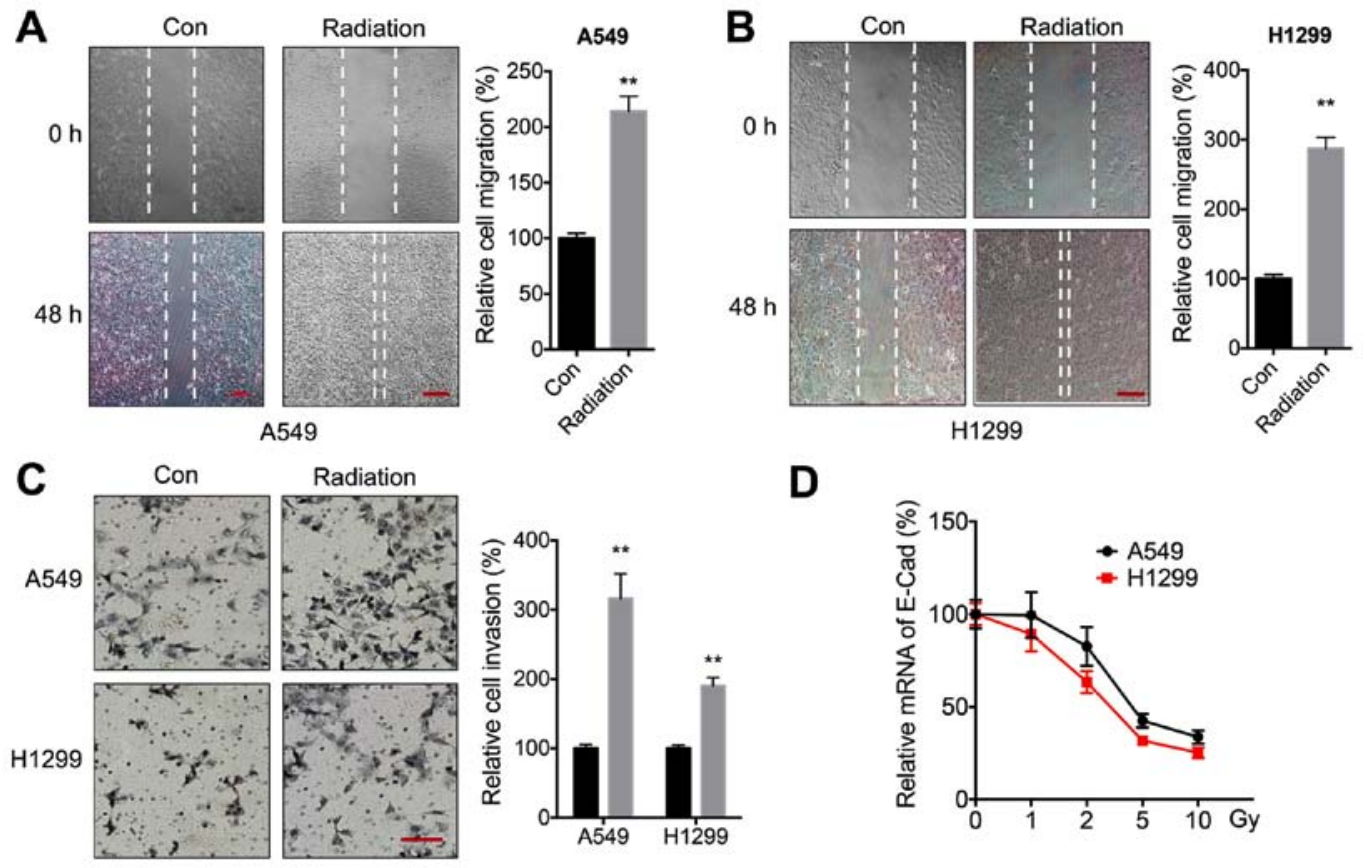

$\mathbf{E}$

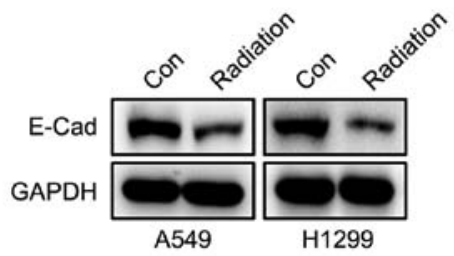

Figure 1. Radiation increases the motility of NSCLC cells. (A and B) Wound healing assay for (A) A549 or (B) H1299 cells treated with 5 Gy radiation (Radiation) or incubated without radiation (Con) for $48 \mathrm{~h}$. Scale bar, $100 \mu \mathrm{m}$. (C) Transwell Matrigel invasion assay for A549 and H1299 cells treated with 5 Gy radiation (Radiation) or incubated without radiation (Con) for $48 \mathrm{~h}$. Scale bar, $100 \mu \mathrm{m}$. (D) E-Cad mRNA expression levels following treatment with increasing doses of radiation for $24 \mathrm{~h}$. (E) E-Cad protein expression levels following treatment with 5 Gy radiation (Radiation) or incubation without radiation (Con) for $24 \mathrm{~h}$. Data are presented as the mean $\pm \mathrm{SD}$ of three independent experiments. ${ }^{* * *} \mathrm{P}<0.01$. NSCLC, non-small cell lung cancer; E-Cad; E-cadherin; Con, control.
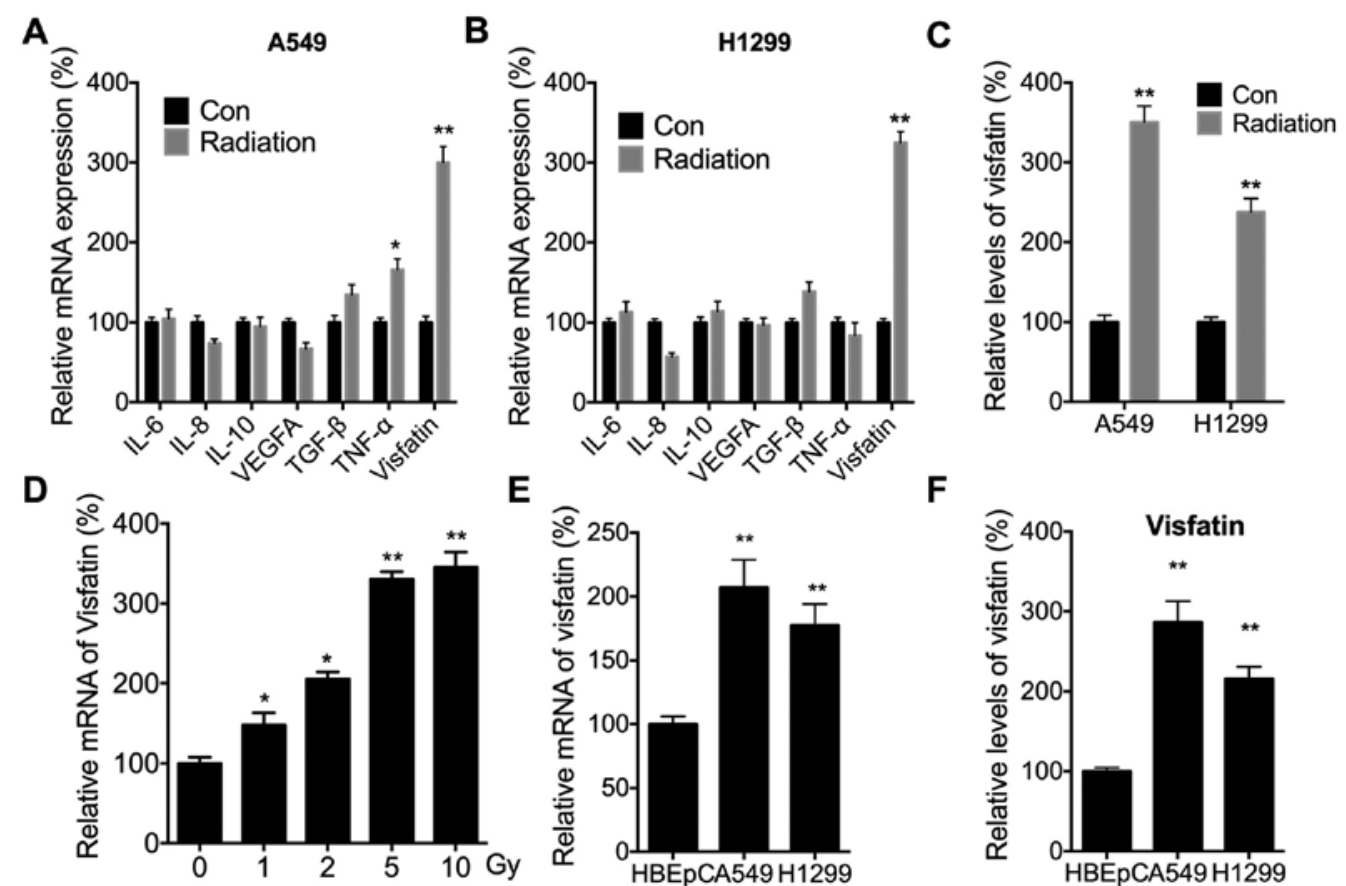

Figure 2. Radiation increases the expression of visfatin in NSCLC cells. (A and B) Cytokine mRNA levels in (A) A549 or (B) H1299 cells treated with 5 Gy radiation (Radiation) or incubated without radiation (Con) for $24 \mathrm{~h}$. (C) Relative levels of visfatin in the culture supernatant of A549 or H1299 cells treated with 5 Gy radiation (Radiation) or incubated without radiation (Con) for $24 \mathrm{~h}$. (D) Visfatin mRNA expression levels and (F) in A549 cells treated with increasing doses of radiation for $24 \mathrm{~h}$. (E) Visfatin mRNA expression levels in HBEpC, A549 and H1299 cells. (F) Relative levels of visfatin in HBEpC, A549 and H1299 cells. Data are presented as the mean \pm SD of three independent experiments. ${ }^{*} \mathrm{P}<0.05,{ }^{* *} \mathrm{P}<0.01$. NSCLC, non-small cell lung cancer; Con, control. 

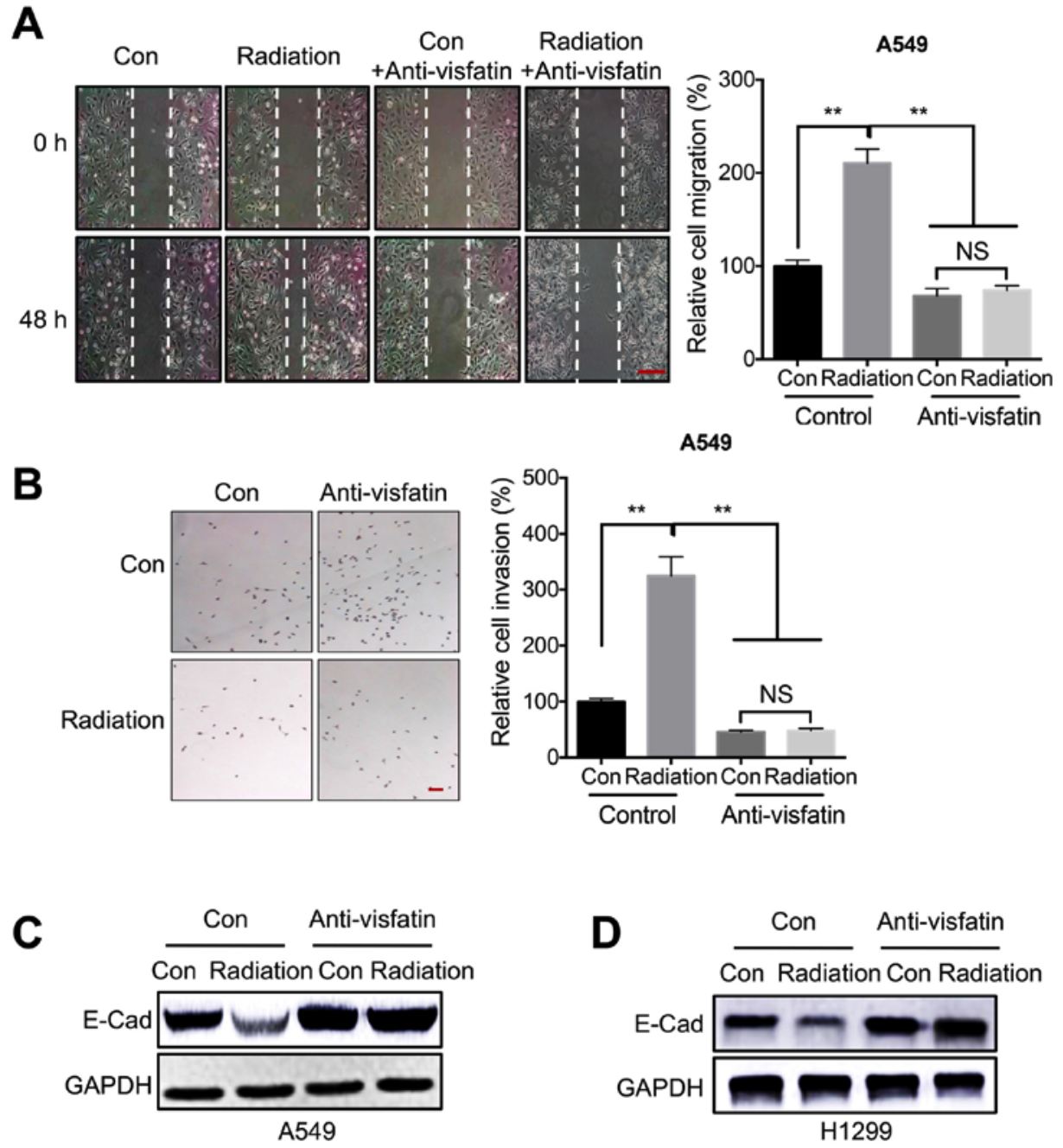

Figure 3. Visfatin is essential for radiation-induced cell motility. (A and B) A549 cells treated with 5 Gy radiation (Radiation) or incubated without radiation (Con) were further incubated with or without $100 \mathrm{ng} / \mathrm{ml}$ anti-visfatin antibody for $48 \mathrm{~h}$. (A) Migration was measured using a wound healing assay. Scale bar, $100 \mu \mathrm{m}$. (B) Invasion was evaluated using a Transwell Matrigel assay. (C and D) A549 and H1299 cells treated with 5 Gy radiation (Radiation) or incubated without radiation (Con) were further incubated with or without $100 \mathrm{ng} / \mathrm{ml}$ anti-visfatin antibody for $48 \mathrm{~h}$. E-Cad protein expression levels were measured in (C) A549 and (D) H1299 cells. Data are presented as the mean \pm SD of three independent experiments. ${ }^{* *} \mathrm{P}<0.01$. E-Cad; E-cadherin; Con, control; NS, not significant.

levels of Snail in both A549 (Fig. 4A) and H1299 (Fig. 4B) cells. Further, western blot analysis confirmed that radiation increased the protein expression levels of Snail in both cell lines (Fig. 4C). However, radiation-induced expression of Snail could be blocked following treatment with the anti-visfatin neutralizing antibody in both A549 (Fig. 4D) and H1299 (Fig. 4E) cells. In addition, Snail siRNA knockdown reversed the radiation-induced downregulation of E-Cad (Fig. 4F).

Visfatin regulates the $m R N A$ stability of Snail. The mechanisms involved in visfatin-mediated regulation of Snail expression were further examined. The anti-visfatin neutralizing antibody decreased the mRNA levels of Snail in both A549 and H1299 cells (Fig. 5A). Conversely, rVisfatin increased Snail mRNA levels in both cell lines (Fig. 5B). Additionally, the mRNA and protein stability of Snail was evaluated in NSCLC cells. The results suggested that anti-visfatin could decrease stability of Snail at the mRNA level in both A549 (Fig. 5C) and H1299 (Fig. 5D) cells following Act-D treatment. However, anti-visfatin had no effect on the stability of Snail protein in A549 cells (Fig. 5E) following CHX treatment.
Visfatin may regulate Snail expression through miR-34a. miRNA molecules can decrease mRNA stability by binding to its 3'-UTR (43). It has been suggested that miR-137 (35), miR-34a (35), miR-153 (44), and miR-22 (45) can directly target Snail mRNA to inhibit its expression and reduce its stability. In the present study, anti-visfatin significantly increased the expression of miR-34a in both A549 (Fig. 6A) and H1299 (Fig. 6B) cells. Similarly, radiation also reduced the expression of miR-34a in both cell lines (Fig. 6C). Moreover, transfection with the miR-34a inhibitor significantly increased the luciferase activities of reporter vector containing the WT Snail 3'-UTR. However, this effect was abrogated following transfection with the MUT Snail 3'UTR, which contained mutations targeting the predicted binding site of miR-34a (Fig. 6D). These results demonstrated the direct binding between miR-34a and the 3'-UTR of Snail. Furthermore, treatment with the anti-visfatin neutralizing antibody reduced the luciferase activity of the reporter vector containing the Snail 3'-UTR, whereas the addition of miR-34a inhibitor abolished this effect (Fig. 6E). The miR-34a inhibitor was then used to evaluate whether miR-34a was involved in visfatin-mediated 
A

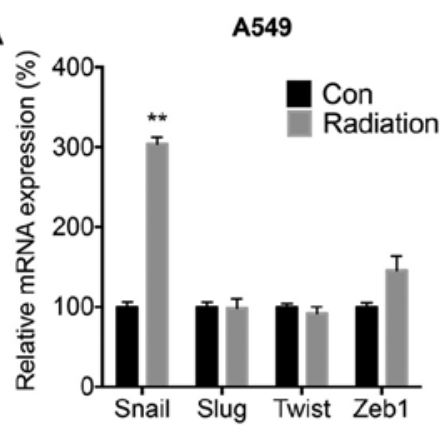

D

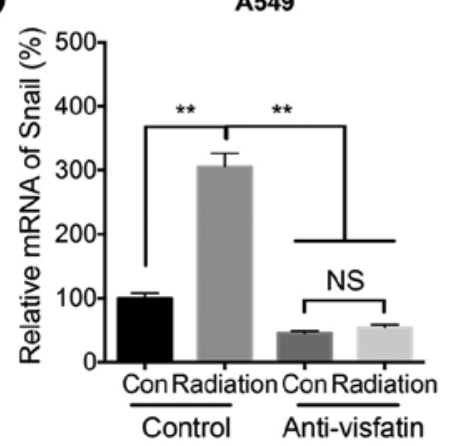

B

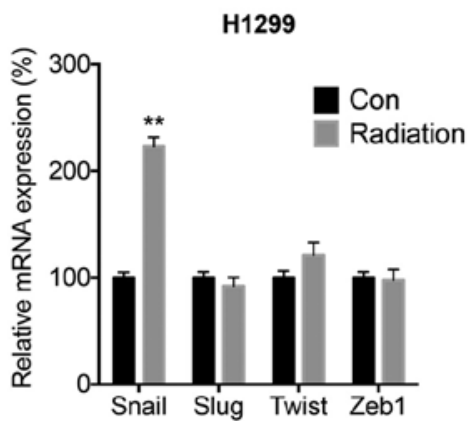

E

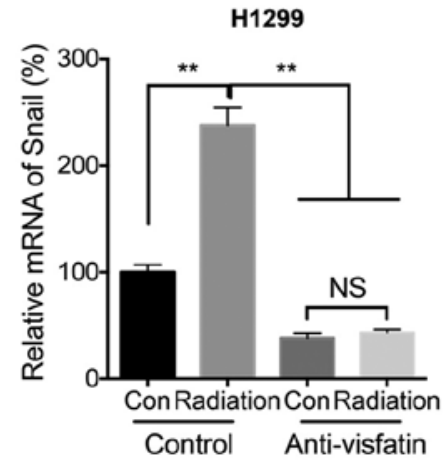

C

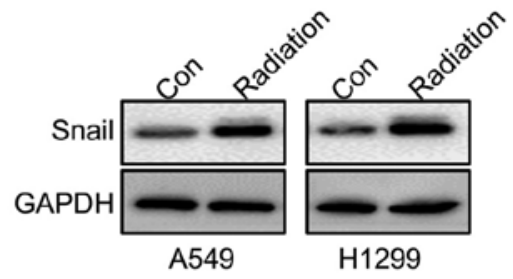

$\mathbf{F}$

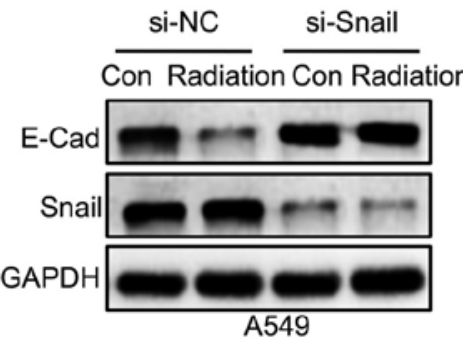

Figure 4. Snail is involved in radiation- and visfatin-induced cell migration. mRNA expression levels of Snail, Slug, Twist and Zeb1 in (A) A549 or (B) H1299 cells treated with 5 Gy radiation (Radiation) or incubated without radiation (Con) for 24 h. (C) Protein expression levels of Snail in A549 or H1299 cells treated with 5 Gy radiation (Radiation) or incubated without radiation (Con) for $24 \mathrm{~h}$. (D and E) Snail mRNA expression levels in (D) A549 and (E) H1299 cells treated with 5 Gy radiation (Radiation) or incubated without radiation (Con) and further incubated with or without $100 \mathrm{ng} / \mathrm{ml}$ anti-visfatin antibody for $48 \mathrm{~h}$. (F) Snail and E-Cad protein expression levels in A549 cells transfected with si-NC or si-Snail for $12 \mathrm{~h}$, then further treated with $5 \mathrm{~Gy}$ radiation (Radiation) or incubated without radiation (Con) for $24 \mathrm{~h}$. Data are presented as the mean \pm SD of three independent experiments. ${ }^{* *} \mathrm{P}<0.01$. E-Cad; E-cadherin; Con, control; NS, not significant; si, small interfering; NC, negative control.

A

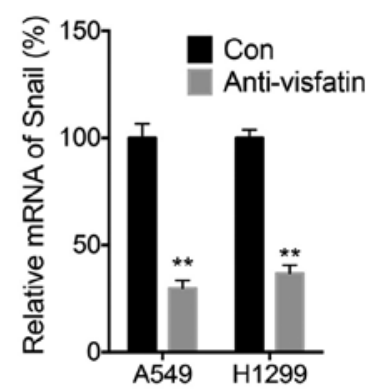

D

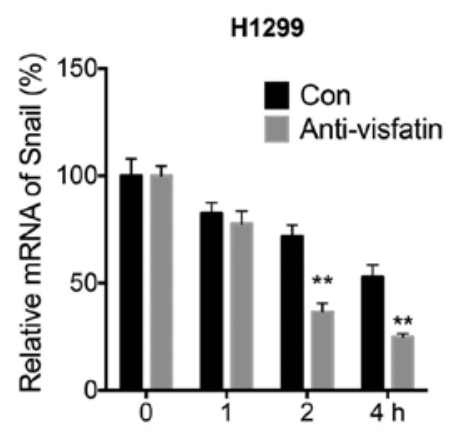

B

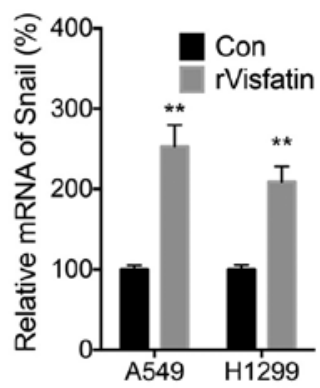

$\mathbf{E}$

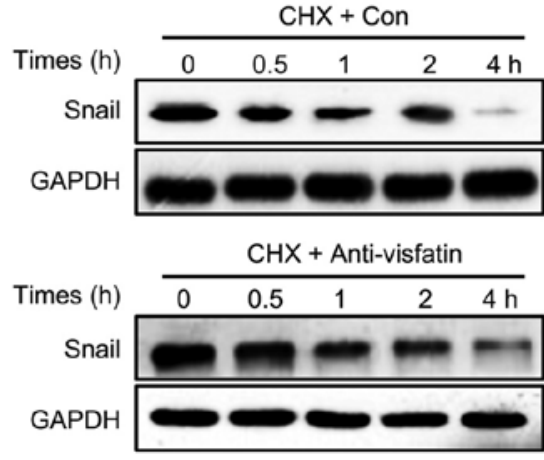

C

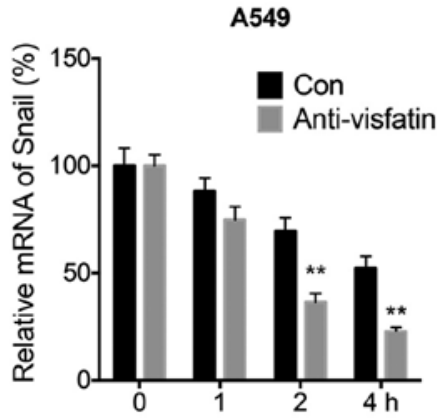

Figure 5. Visfatin regulates the stability of Snail at the mRNA level. (A) Snail mRNA expression levels in cells treated with (Anti-visfatin) or without (Con) $100 \mathrm{ng} / \mathrm{ml}$ anti-visfatin antibody for $48 \mathrm{~h}$. (B) Snail mRNA expression levels in cells treated with (rVisfatin) or without (Con) $100 \mathrm{ng} / \mathrm{ml} \mathrm{rVisfatin}$ for $24 \mathrm{~h}$. (C and D) Snail mRNA expression levels in (C) A549 and (D) H1299 cells pre-treated with (Anti-visfatin) or without (Con) 100 ng/ml anti-visfatin antibody for $24 \mathrm{~h}$ and further treated with Act-D for the indicated time periods. (E) Snail protein expression levels in A549 cells pre-treated with (Anti-visfatin) or without (Con) $100 \mathrm{ng} / \mathrm{ml}$ anti-visfatin for $24 \mathrm{~h}$ and further treated with $10 \mu \mathrm{g} / \mathrm{ml} \mathrm{CHX}$ for the indicated times. Data are presented as the mean \pm SD of three independent experiments. ${ }^{* *} \mathrm{P}<0.01$. rVisfatin, recombinant visfatin; Act-D, actinomycin-D, CHX, cycloheximide. 

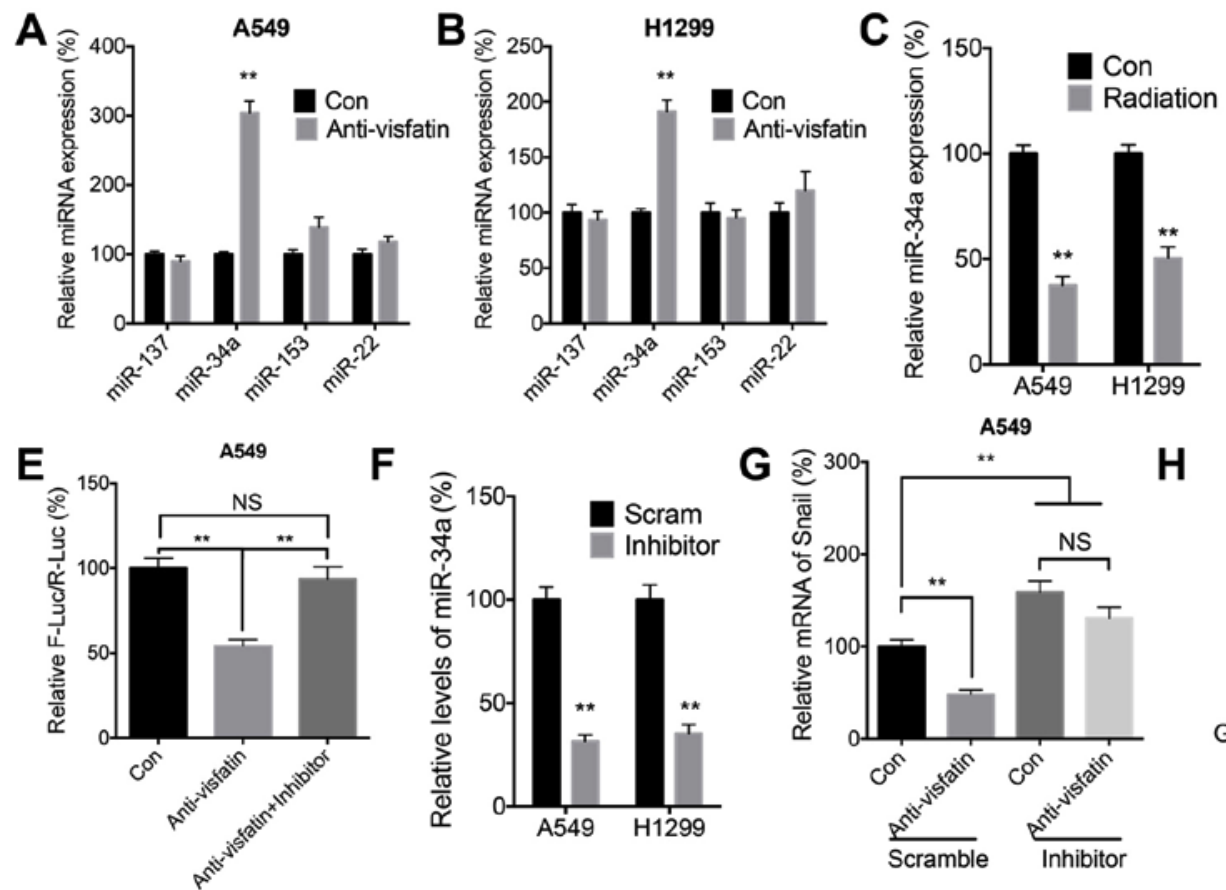

H
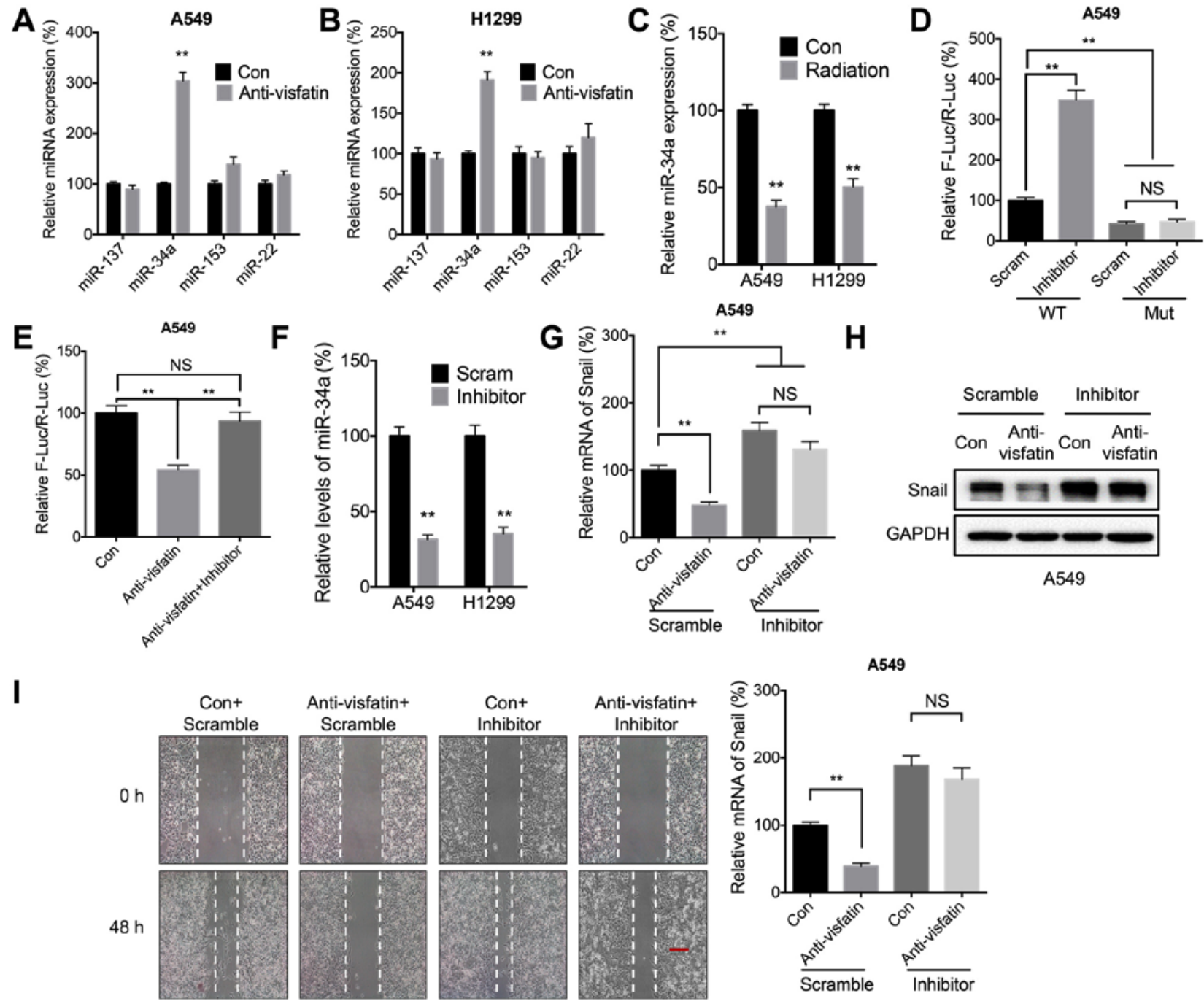

Figure 6. miR-34a may be involved in visfatin-regulated expression of Snail. (A and B) miR expression levels in (A) A549 and (B) H1299 cells treated with (Anti-visfatin) or without (Con) $100 \mathrm{ng} / \mathrm{ml}$ anti-visfatin antibody for $48 \mathrm{~h}$. (C) miR-34a expression levels in cells treated with (Radiation) or without (Con) 5 Gy radiation for $24 \mathrm{~h}$. (D) Luciferase activity in A549 cells co-transfected with WT or MUT Snail-3'-UTR Firefly luciferase reporter plasmid and Scram or miR-34a inhibitor for $24 \mathrm{~h}$. (E) A549 cells were co-transfected with WT Snail-3'-UTR Firefly luciferase reporter plasmid with or without miR-34a inhibitor for $12 \mathrm{~h}$. The Anti-visfatin and Anti-visfatin + inhibitor groups were treated with $100 \mathrm{ng} / \mathrm{ml}$ anti-visfatin antibody for $24 \mathrm{~h}$. (F) miR-34a expression levels in cells transfected with Scram miR or miR-34a inhibitor for $24 \mathrm{~h}$. (G-I) A549 cells were pre-transfected with Scram or miR-34a inhibitor for $12 \mathrm{~h}$, then treated with (Anti-visfatin) or without (Con) $100 \mathrm{ng} / \mathrm{ml}$ anti-visfatin antibody for $48 \mathrm{~h}$. (G) mRNA and (H) protein expression levels of Snail. (I) Relative cell migration. Scale bar, $100 \mu \mathrm{m}$. Data are presented as the mean $\pm \mathrm{SD}$ of three independent experiments. ${ }^{* *} \mathrm{P}<0.01$. Con, control; Scram; scramble control; WT, wild-type; MUT, mutant; UTR, unstranslated region; miR, microRNA; F-Luc, Firefly luciferase; R-Luc, Renilla luciferase; NS, not significant.

regulation of Snail expression (Fig. 6F). The results showed that the miR-34a inhibitor could reverse the downregulation of Snail mRNA (Fig. 6G) and protein (Fig. 6H) induced by visfatin blockade in A549 cells. In addition, the miR-34a inhibitor promoted migration and reversed the effect of the anti-visfatin antibody on the migration of A549 cells (Fig. 6I).

\section{Discussion}

Although radiotherapy is widely used for NSCLC treatment, the efficacy of this therapeutic approach is not always satisfactory, even in the absence of radioresistance (8). Previous studies have indicated that residual cancer cells cancer survive following radiotherapy in many cancer types and become more malignant $(46,47)$. For instance, radiation can increase the metastatic ability of cancer cells through the induction of EMT $(48,49)$. In the present study, radiation was found to induce the migration and invasion of NSLC cells, as evidenced by the results of wound healing assays and invasion assays, as well as E-Cad downregulation. Similarly, previous studies have demonstrated that radiation could upregulate MMP-2 and MMP-9 in NSCLC cells, resulting in increased invasion and migration of lung cancer cells $(13,50) . \gamma$-ionizing radiation (IR) also induces migration/invasion of NSCLC cells (51). Thus, consistent with previous reports, our present findings highlighted the potential adverse effects of radiotherapy on NSCLC progression.

In the present study, visfatin was essential for radiation-induced motility of NSCLC cells. Visfatin has been reported to regulate angiogenesis, inflammation, and cell viability (52). A study has indicated that expression of visfatin is increased in cancer tissues as compared to that in the normal tissues (53). Furthermore, visfatin promotes the invasion and migration of several cancer types, such as 
hepatocellular carcinoma (54) and colorectal carcinoma (55). It is also involved in resistance to Dox treatment in colorectal cancer (56). Visfatin is upregulated in lung cancer cells and tissues (42); it also regulates the EMT and invasion of NSCLC cells (18), as well as Dox sensitivity (17). In the present study, visfatin was upregulated after radiation therapy, and visfatin blockade with a neutralizing attenuated radiation-induced cell motility. This suggested that visfatin could promote the malignancy of lung cancer.

The present study revealed that miR-34a/Snail is involved in visfatin-regulated radiotherapy-induced malignancy of NSCLC cells. Moreover, it has been reported that visfatin can upregulate the expression of Snail to induce EMT-like properties in osteosarcoma cells (57) and colorectal cancer (55). In NSCLC cells, visfatin upregulates Snail expression by increasing its mRNA stability, likely by decreasing the expression of miR-34a. Previous studies have indicated that Snail was the direct target of miR-34a in gastric (58), pancreatic (59), and ovarian (35) cancer cells. In addition, Snail directly induces ZNF281 transcription and represses $\mathrm{miR}-34 \mathrm{a} / \mathrm{b} / \mathrm{c}$, thereby alleviating ZNF281 mRNA from direct down-regulation by miR-34 and promoting the EMT of lung cancer cells (60). However, the mechanisms underlying visfatin-regulated expression of miR-34a remain unclear.

In summary, the present study demonstrated that radiation increased the malignancy of NSCLC cells through visfatin upregulation. miR-34a-regulated mRNA stability of Snail and was involved in radiation/visfatin regulated motility of NSCLC cells. Although the detailed mechanisms underlying the role of visfatin and miR-34a remain to be determined, these findings highlighted the adverse effects of radiotherapy on NSCLC cell motility.

\section{Acknowledgements}

No applicable.

\section{Funding}

This work was supported by The National Natural Science Foundation of China (grant no. 81673099).

\section{Availability of data and materials}

The datasets used and/or analyzed during the current study are available from the corresponding author on reasonable request.

\section{Authors' contributions}

LX, YM, ZT, YZ, HH and FW conceived and designed the study. LX, YM and FW acquired the data. LX, YM and $\mathrm{HH}$ analyzed and interpreted the data. LX, HH and FW wrote, reviewed and revised the manuscript. All authors read and approved the final manuscript. LX and FW confirm the authenticity of the raw data. All authors read and approved the final manuscript.

\section{Ethics approval and consent to participate}

Not applicable.

\section{Patient consent for publication}

Not applicable.

\section{Competing interests}

The authors declare that they have no competing interests.

\section{References}

1. Askoxylakis V, Thieke C, Pleger ST, Most P, Tanner J, Lindel K, Katus HA, Debus J and Bischof M: Long-term survival of cancer patients compared to heart failure and stroke: A systematic review. BMC Cancer 10: 105, 2010.

2. Schwartz AG, Wenzlaff AS, Prysak GM, Murphy V, Cote ML, Brooks SC, Skafar DF and Lonardo F: Reproductive factors, hormone use, estrogen receptor expression and risk of non small-cell lung cancer in women. J Clin Oncol 25: 5785-5792, 2007.

3. Gondos A, Bray F, Brewster DH, Coebergh JW, Hakulinen T, Janssen-Heijnen ML, Kurtinaitis J and Brenner H; EUNICE Survival Working Group: Recent trends in cancer survival across Europe between 2000 and 2004: A model-based period analysis from 12 cancer registries. Eur J Cancer 44: 1463-1475, 2008.

4. Molina JR, Yang P, Cassivi SD, Schild SE and Adjei AA: Non-small cell lung cancer: Epidemiology, risk factors, treatment, and survivorship. Mayo Clin Proc 83: 584-594, 2008.

5. Remon J, Ahn MJ, Girard N, Johnson M, Kim DW, Lopes G, Pillai RN, Solomon B, Villacampa G and Zhou Q: Advanced-stage non-small cell lung cancer: Advances in thoracic oncology 2018. J Thorac Oncol 14: 1134-1155, 2019.

6. Antonia SJ, Villegas A, Daniel D, Vicente D, Murakami S, Hui R, Yokoi T, Chiappori A, Lee KH, de Wit M, et al; PACIFIC investigators: Durvalumab after chemoradiotherapy in stage III non-small-cell lung cancer. N Engl J Med 377: 1919-1929, 2017.

7. Shinde A, Li R, Kim J, Salgia R, Hurria A and Amini A: Stereotactic body radiation therapy (SBRT) for early-stage lung cancer in the elderly. Semin Oncol 45: 210-219, 2018.

8. Draghiciu O, Walczak M, Hoogeboom BN, Franken KL, Melief KJ, Nijman HW and Daemen T: Therapeutic immunization and local low-dose tumor irradiation, a reinforcing combination. Int J Cancer 134: 859-872, 2014.

9. Lee S, Lim MJ, Kim MH, Yu CH, Yun YS, Ahn J and Song JY: An effective strategy for increasing the radiosensitivity of human lung cancer cells by blocking Nrf2-dependent antioxidant responses. Free Radic Biol Med 53: 807-816, 2012.

10. Provencio M, Sánchez A, Garrido $P$ and Valcárcel F: New molecular targeted therapies integrated with radiation therapy in lung cancer. Clin Lung Cancer 11: 91-97, 2010.

11. Rube CE, Uthe D, Schmid KW, Richter KD, Wessel J, Schuck A, Willich $\mathrm{N}$ and Rube C: Dose-dependent induction of transforming growth factor beta (TGF-beta) in the lung tissue of fibrosis-prone mice after thoracic irradiation. Int J Radiat Oncol Biol Phys 47: 1033-1042, 2000.

12. Tsukamoto H, Shibata K, Kajiyama H, Terauchi M, Nawa A and Kikkawa F: Irradiation-induced epithelial-mesenchymal transition (EMT) related to invasive potential in endometrial carcinoma cells. Gynecol Oncol 107: 500-504, 2007.

13. Zhao Q, Mao A, Guo R, Zhang L, Yan J, Sun C, Tang J, Ye Y, Zhang Y and Zhang H: Suppression of radiation-induced migration of non-small cell lung cancer through inhibition of Nrf2-Notch Axis. Oncotarget 8: 36603-36613, 2017.

14. Kroeze SG, van Melick HH, Nijkamp MW,Kruse FK, Kruijssen LW, van Diest PJ, Bosch JL and Jans JJ: Incomplete thermal ablation stimulates proliferation of residual renal carcinoma cells in a translational murine model. BJU Int 110: E281-E286, 2012.

15. Shiozawa K, Watanabe M, Takahashi M, Wakui N, Iida K and Sumino Y: Analysis of patients with rapid aggressive tumor progression of hepatocellular carcinoma after percutaneous radiofrequency ablation. Hepatogastroenterology 56: 1689-1695, 2009.

16. Daly ME, Monjazeb AM and Kelly K: Clinical trials integrating immunotherapy and radiation for non-small-cell lung cancer. J Thorac Oncol 10: 1685-1693, 2015.

17. Cao Z, Liang N, Yang H and Li S: Visfatin mediates doxorubicin resistance in human non-small-cell lung cancer via Akt-mediated up-regulation of ABCC1. Cell Prolif 50: e12366, 2017. 
18. Wang G, Tian W, Liu Y, Ju Y, Shen Y, Zhao S, Zhang B and $\mathrm{Li}$ Y: Visfatin triggers the cell motility of non-small cell lung cancer via up-regulation of matrix metalloproteinases. Basic Clin Pharmacol Toxicol 119: 548-554, 2016.

19. Okumura S, Sasaki T, Minami Y and Ohsaki Y: Nicotinamide phosphoribosyltransferase: A potent therapeutic target in non-small cell lung cancer with epidermal growth factor receptor-gene mutation. J Thorac Oncol 7: 49-56, 2012.

20. Laiguillon MC, Houard X, Bougault C, Gosset M, Nourissat G Sautet A, Jacques C, Berenbaum F and Sellam J: Expression and function of visfatin (Nampt), an adipokine-enzyme involved in inflammatory pathways of osteoarthritis. Arthritis Res Ther 16: R38, 2014.

21. Gujar AD, Le S, Mao DD, Dadey DY, Turski A, Sasaki Y, Aum D, Luo J, Dahiya S, Yuan L, et al: An NAD ${ }^{+}$-dependent transcriptional program governs self-renewal and radiation resistance in glioblastoma. Proc Natl Acad Sci USA 113: E8247-E8256, 2016.

22. Xiang B, Han L, Wang X, Tang L, Li K, Li X, Zhao X, Xia M, Zhou X, Zhang F, et al: Nicotinamide phosphoribosyltransferase upregulation by phenylephrine reduces radiation injury in submandibular gland. Int J Radiat Oncol Biol Phys 96: 538-546, 2016.

23. Thiery JP: Epithelial-mesenchymal transitions in tumour progression. Nat Rev Cancer 2: 442-454, 2002

24. Lu W and Kang Y: Epithelial-mesenchymal plasticity in cancer progression and metastasis. Dev Cell 49: 361-374, 2019.

25. Batlle E, Sancho E, Francí C, Domínguez D, Monfar M, Baulida J and García De Herreros A: The transcription factor snail is a repressor of E-cadherin gene expression in epithelial tumour cells. Nat Cell Biol 2: 84-89, 2000

26. Xu J, Lamouille S and Derynck R: TGF-beta-induced epithelial to mesenchymal transition. Cell Res 19: 156-172, 2009.

27. Wang G, Ma W, Li Y, Jiang Y, Ma G, Zhang X, Meng L and $\mathrm{Du}$ J: Prognostic value of Twist, Snail and E-cadherin expression in pathological N0 non-small-cell lung cancer: A retrospective cohort study. Eur J Cardiothorac Surg 54: 237-245, 2018.

28. Yanagawa J, Walser TC, Zhu LX, Hong L, Fishbein MC, Mah V, Chia D, Goodglick L, Elashoff DA, Luo J, et al: Snail promotes CXCR2 ligand-dependent tumor progression in non-small cell lung carcinoma. Clin Cancer Res 15: 6820-6829, 2009.

29. Zhang Y, Zhang X, Ye M, Jing P, Xiong J, Han Z, Kong J, Li M, Lai X, Chang N, et al: FBW7 loss promotes epithelial-to-mesenchymal transition in non-small cell lung cancer through the stabilization of Snail protein. Cancer Lett 419: 75-83, 2018.

30. Lin Y, Bai X, Zhou W, He Y, Wu Y and Wang X: Radiation exposure triggers the progression of triple negative breast cancer via stabilizing ZEB1. Biomed Pharmacother 107: 1624-1630, 2018.

31. Wang Q, Yang G, Jiang Y, Luo M, Li C, Zhao Y, Xie Y, Song K and Zhou J: XB130, regulated by miR-203, miR-219, and miR-4782-3p, mediates the proliferation and metastasis of non-small-cell lung cancer cells. Mol Carcinog 59: 557-568, 2020

32. Livak KJ and Schmittgen TD: Analysis of relative gene expression data using real-time quantitative PCR and the 2(-Delta Delta C(T)) method. Methods 25: 402-408, 2001.

33. Pecoraro A, Carotenuto P, Russo G and Russo A: Ribosomal protein $\mathrm{uL} 3$ targets E2F1 and Cyclin D1 in cancer cell response to nucleolar stress. Sci Rep 9: 15431, 2019.

34. Lu L, Chen Z, Lin X, Tian L, Su Q, An P, Li W, Wu Y, Du J Shan $\mathrm{H}$, et al: Inhibition of BRD4 suppresses the malignancy of breast cancer cells via regulation of Snail. Cell Death Differ 27: 255-268, 2020

35. Dong P, Xiong Y, Watari H, Hanley SJ, Konno Y, Ihira K, Yamada T, Kudo M, Yue J and Sakuragi N: MiR-137 and miR-34a directly target Snail and inhibit EMT, invasion and sphere-forming ability of ovarian cancer cells. J Exp Clin Cancer Res 35: 132, 2016

36. Kim R-K, Kaushik N, Suh Y, Yoo KC, Cui YH, Kim MJ, Lee HJ, Kim IG and Lee SJ: Radiation driven epithelial-mesenchymal transition is mediated by Notch signaling in breast cancer. Oncotarget 7: 53430-53442, 2016

37. Feys L, Descamps B, Vanhove C, Vral A, Veldeman L, Vermeulen S De Wagter C, Bracke M and De Wever O: Radiation-induced lung damage promotes breast cancer lung-metastasis through CXCR4 signaling. Oncotarget 6: 26615-26632, 2015.

38. Lagadec C, Vlashi E, Della Donna L, Dekmezian C and Pajonk F: Radiation-induced reprogramming of breast cancer cells. Stem Cells 30: 833-844, 2012.

39. Rodriguez-Ruiz ME, Vitale I, Harrington KJ, Melero I and Galluzzi L: Immunological impact of cell death signaling driven by radiation on the tumor microenvironment. Nat Immunol 21: $120-134,2020$
40. Strieter RM, Belperio JA, Burdick MD, Sharma S, Dubinett SM and Keane MP: CXC chemokines: Angiogenesis, immunoangiostasis, and metastases in lung cancer. Ann NY Acad Sci 1028: 351-360, 2004.

41. Santaniello A, Napolitano F, Servetto A, De Placido P, Silvestris N, Bianco C, Formisano L and Bianco R: Tumour microenvironment and immune evasion in EGFR addicted NSCLC: Hurdles and possibilities. Cancers (Basel) 11: 1419, 2019.

42. Liu T, Miao Z, Jiang J, Yuan S, Fang W, Li B and Chen Y: Visfatin mediates SCLC cells migration across brain endothelial cells through upregulation of CCL2. Int J Mol Sci 16: 11439-11451, 2015.

43. Uddin A and Chakraborty S: Role of miRNAs in lung cancer. J Cell Physiol: Apr 20, 2018 (Epub ahead of print). doi: 10.1002/jcp.26607.

44. Wang $\mathrm{Z}$ and Liu C: MiR-153 regulates metastases of gastric cancer through Snail. Tumour Biol 37: 15509-15515, 2015.

45. Zhang K, Li XY, Wang ZM, Han ZF and Zhao YH: MiR-22 inhibits lung cancer cell EMT and invasion through targeting Snail. Eur Rev Med Pharmacol Sci 21: 3598-3604, 2017.

46. Cui YH, Suh Y, Lee HJ, Yoo KC, Uddin N, Jeong YJ, Lee JS, Hwang SG, Nam SY, Kim MJ, et al: Radiation promotes invasiveness of non-small-cell lung cancer cells through granulocyte-colony-stimulating factor. Oncogene 34: 5372-5382, 2015.

47. Qian L-W, Mizumoto K, Urashima T, Nagai E, Maehara N, Sato N, Nakajima M and Tanaka M: Radiation-induced increase in invasive potential of human pancreatic cancer cells and its blockade by a matrix metalloproteinase inhibitor, CGS27023. Clin Cancer Res 8: 1223-1227, 2002.

48. Nambiar DK, Rajamani P and Singh RP: Silibinin attenuates ionizing radiation-induced pro-angiogenic response and EMT in prostate cancer cells. Biochem Biophys Res Commun 456: 262-268, 2015.

49. Zhou YC, Liu JY, Li J, Zhang J, Xu YQ, Zhang HW, Qiu LB, Ding GR, Su XM, Mei-Shi, et al: Ionizing radiation promotes migration and invasion of cancer cells through transforming growth factor-beta-mediated epithelial-mesenchymal transition. Int J Radiat Oncol Biol Phys 81: 1530-1537, 2011.

50. Wang L, Zhao Y, Xiong Y, Wang W, Fei Y, Tan C and Liang Z: $\mathrm{K}$-ras mutation promotes ionizing radiation-induced invasion and migration of lung cancer in part via the Cathepsin L/CUX1 pathway. Exp Cell Res 362: 424-435, 2018.

51. Cho JH, Hong WG, Jung YJ, Lee J, Lee E, Hwang SG, Um HD and Park JK: $\gamma$-Ionizing radiation-induced activation of the EGFR-p38/ ERK-STAT3/CREB-1-EMT pathway promotes the migration/ invasion of non-small cell lung cancer cells and is inhibited by podophyllotoxin acetate. Tumour Biol 37: 7315-7325, 2016.

52. Romacho T, Sánchez-Ferrer CF and Peiró C: Visfatin/Nampt: An adipokine with cardiovascular impact. Mediators Inflamm 2013: 946427, 2013

53. Carbone F, Liberale L, Bonaventura A, Vecchiè A, Casula M, Cea M, Monacelli F, Caffa I, Bruzzone S, Montecucco F, et al: Regulation and function of extracellular nicotinamide phosphoribosyltransferase/visfatin. Compr Physiol 7: 603-621, 2017.

54. Liang N, Chen Y, Yang L, He S and Liu T: Visfatin increases miR-21 to promote migration in HCC. Cell Mol Biol 64: 48-52, 2018.

55. Yang J, Zhang K, Song H, Wu M, Li J, Yong Z, Jiang S, Kuang X and Zhang T: Visfatin is involved in promotion of colorectal carcinoma malignancy through an inducing EMT mechanism. Oncotarget 7: 32306-32317, 2016.

56. Yan X, Zhao J and Zhang R: Visfatin mediates doxorubicin resistance in human colorectal cancer cells via up regulation of multidrug resistance 1 (MDR1). Cancer Chemother Pharmacol 80: 395-403, 2017.

57. Wang D, Qian G, Wang J, Wang T, Zhang L, Yang P and Lin F: Visfatin is involved in the cisplatin resistance of osteosarcoma cells via upregulation of Snail and Zeb1. Cancer Biol Ther 20: 999-1006, 2019.

58. Zhang Y, Yuan Y, Zhang Y, Cheng L, Zhou X and Chen K: SNHG7 accelerates cell migration and invasion through regulating miR-34a-Snail-EMT axis in gastric cancer. Cell Cycle 19: 142-152, 2020.

59. Tang Y, Tang Y and Cheng YS: miR-34a inhibits pancreatic cancer progression through Snaill-mediated epithelial-mesenchymal transition and the Notch signaling pathway. Sci Rep 7: 38232, 2017.

60. Hahn S, Jackstadt R, Siemens H, Hünten S and Hermeking H: SNAIL and miR-34a feed-forward regulation of ZNF281/ZBP99 promotes epithelial-mesenchymal transition. EMBO J 32: 3079-3095, 2013.

This work is licensed under a Creative Commons Attribution-NonCommercial-NoDerivatives 4.0 International (CC BY-NC-ND 4.0) License. 